\title{
A Rotulação da Adolescente Infratora em Sentenças de Juízes e Juízas de Direito do Distrito Federal
}

\author{
The Rotulation of Female Young Offenders as they are Sentenced in a \\ Brazilian Court
}

\author{
Marília Montenegro Pessoa de Melo \\ Universidade Católica de Pernambuco, Recife - PE, Brasil
}

\author{
Manuela Abath Valenca \\ Universidade de Brasília, Brasília - DF, Brasil
}

\begin{abstract}
Resumo: o presente trabalho explorou o conjunto de representações sociais de magistrados e de magistradas do TJDFT sobre as trajetórias das adolescentes em cumprimento de medida $j$ socioeducativa de internação na Unidade de Internação de Santa Maria, procurando compreender como essa categoria de adolescentes infratoras é construída em sentenças. Para tanto, realizou-se uma análise de conteúdo em 17 sentenças. Verificou-se que há uma ênfase na descrição das "trajetórias perdidas" das meninas no processo de fundamentação da medida de internação. A relação criada entre essa "carreira de indisciplinas" e a medida de internação tem um papel positivo de constituição desse sujeito criminal, nomeando-se o tipo social de quem se espera o comportamento criminoso.
\end{abstract}

Palavras-chave: Representações Sociais. Magistrados. Adolescentes. Sujeição Criminal.

\begin{abstract}
: this study explores the social representations of judges of the TJDFT about the trajectories of inmates of Santa Maria Unit - a juvenile prison for girls. We tried to understand how this category of offenders teenagers is constructed on the sentences. To do so, we performed a content analysis of 17 sentences. We found that there is an emphasis on the description of the "lost trajectories" of these girls. Their "career of indisciplines" justifies the detention and the sentences have a positive role in the constitution of criminal subject, naming the social type from who we can expect criminal behavior.
\end{abstract}

Keywords: Social Representation. Judges. Young.

Recebido em: 04/11/2015

Revisado em: 19/03/2016

Aprovado em: 27/03/2016 


\section{Introdução}

A teoria do etiquetamento incorporou aos estudos sobre o desvio uma preocupação central nos processos de interação mediante os quais: a) comportamentos são definidos como desviantes; b) as pessoas são definidas como tipos desviantes; e c) que reações são tomadas em relação a esses comportamentos e pessoas. A atribuição de rótulos de desviantes a determinadas condutas e pessoas, portanto, é fruto dessa rede complexa de negociações de sentido que envolve sujeitos com diferentes capitais político e simbólico.

No Brasil, a construção desse tipo social desviante pelas instâncias do sistema de justiça relaciona a pobreza ao crime, com um forte elemento racial. A adesão, no século XIX, às premissas do positivismo criminológico reforçou teses anteriores acerca da degeneração de algumas raças, criando um campo fértil à noção do tipo biológico criminoso. Nina Rodrigues e a sua teoria da incapacidade biológica dos povos negro e indígena para compreender as regras de uma sociedade civilizada são um bom exemplo de como a criminologia atribui a esses grupos o status privilegiado de perigo.

Os estudos sobre a repressão à vadiagem no início da Era Republicana são elucidativos nesse sentido. $\mathrm{O}$ tipo perigoso estava especificamente descrito na pessoa do pobre, que vaga pelas ruas e "negava" uma ética do trabalho. À polícia cabia passar boa parte de seu tempo em busca de "desordeiros", prostitutas, embriagados e vadios. Na justiça infracional, observa-se essas esquematizações. Estudos recentes sobre o padrão de atuação punitivo sobre adolescentes aponta para uma tendência, no início do século XX, em apreender adolescentes relacionados a ocorrências de embriaguez, vadiagem e prostituição.

A justiça juvenil de matriz tutelar manuseava a categoria de "menor" e, com ela, a representação de uma juventude vulnerável, sobre em quem deveriam recair as instâncias de controle. A doutrina da proteção integral representou um esforço em torno da superação da construção do menor. Porém, diversas pesquisas vêm atentando para o fato de que o tipo 
juvenil infrator ainda é bastante relacionado aos elementos anteriormente citados de classe e raça.

Desse modo, o tema das representações sociais se tornam imprescindíveis para pensar o desvio. Quem é essa adolescente? Como ela cresceu e viveu? O que a levou à prática do ato infracional? Ela tem família? Ela tem futuro? Todas essas perguntas pareceram nortear a atividade decisória de juízes e juízas do Tribunal de Justiça do Distrito Federal e dos Territórios (TJDFT) que aplicaram medida de internação às adolescentes do sexo feminino.

O presente trabalho objetivou explorar o processo de construção social da imagem da adolescente que cumprem medida socioeducativa de internação no Distrito Federal, na Unidade de Santa Maria. Para tanto, realizou-se uma análise de conteúdo em 17 sentenças. Trabalhou-se com a categoria "trajetória desviante", que, em grande medida, era como os operadores da justiça viam as meninas. Partindo dessa categoria, foram estabelecidas mais algumas subcategorias relacionadas, dentre elas: desestrutura familiar, evasão escolar e uso de drogas.

Observa-se nas decisões a valorização desses elementos e a construção de um raciocínio que alia a situação de vulnerabilidade à criminalidade. Assim, duas conclusões parecem perversas: adolescentes pobres e negras são potenciais criminosas e, diante de suas trajetórias, não há mais nada a fazer, a não ser intervir de maneira intensa sobre suas vidas, aplicando a medida socioeducativa de internação.

Para os/as magistrados/as, a "trajetória desviante" das adolescentes inicia-se com a desestrutura familiar e perpassa a evasão escolar e o uso de drogas. Todos esses elementos, junto ao ato infracional, compõem uma espécie de "carreira de indisciplinas" dessas garotas. Percebe-se, ainda, nas falas dos/as julgares a frequente referência a termos como "personalidade", "estímulo infracional", "instinto", perfazendo uma imagem da mulher delinquente com o qual a criminologia tradicional sempre operou.

Em um primeiro momento, foi traçada uma breve explanação acerca da justiça juvenil no Brasil e da dificuldade de recepção dos discursos que orientam a doutrina da proteção integral. Em seguida, foram apresentados os nossos achados de campo, discutindo-os também a partir do mar- 
co da criminologia crítica e, por fim, foi resgatado o conceito de "sujeição criminal" de Michel Misse e de "anormais" em Michel Foucault para pensar as sentenças como um ato de nomeação do tipo social criminoso.

\section{Ser Adolescente e ser Menina: considerações a partir do mar- co teórico da criminologia crítica}

A criminologia crítica provocou uma reviravolta na abordagem do crime e dos processos de criminalização. Deixando de lado as concepções essencializadoras sobre o desvio ${ }^{1}$, atentará para os processos mediante os quais condutas e pessoas passam a ser etiquetadas como criminosas.

As criminologias críticas partem da concepção de que as agências de controle penal não atuam de forma isonômica, selecionam preferencialmente sujeitos pertencentes à classe social mais pobre e às minorias étnicas, operam com enorme violência e baixíssimo grau de adesão às leis e reproduzem as desigualdades existentes em nossa sociedade. A leitura é válida para os variados sistemas de controle, dentre eles, o juvenil.

$\mathrm{O}$ direito penal juvenil ou direito infracional está desenhado na Constituição Federal. Ela representa a consagração, no Brasil, da Doutrina da Proteção Integral, estabelecida em um conjunto de documentos internacionais que versam sobre direitos da infância e juventude. Os pro-

\footnotetext{
${ }^{1}$ A inspiração direta das criminologias críticas é a Teoria do Etiquetamento ou labeling approach, marco construído nas décadas de 1950 e 1960 nos Estados Unidos a partir das premissas do interacionismo simbólico, que compreende a realidade social como constituída a partir dos micro processos de interação interpessoal. O desvio, portanto, antes de se constituir como um dado ontológico e pré-discursivo, é formado e socialmente determinado nos processos de relação em que alguns sujeitos definem certos atos como desviantes, estes atribuídos a outros sujeitos (KITSUSE, 1964, p. 88). Os processos de significação de condutas torna-se fundamental. As minúcias desses processos são largamente desenvolvidos nas obras de Howard Becker, Edwin Schur, Edwin Lemert e outros. Os criminólogos críticos, inicialmente, a partir de um referencial marxista, vão ler esses processos de criminalização a partir dos conflitos estabelecidos entre classes operária e burguesa. Assim, esses últimos se utilizam do crime como mecanismo de perseguição e controle da classe operária. Outras vertentes serão possíveis na criminologia crítica, fundando-se também em paradigmas conflituais, mas não necessariamente marxistas, como é o caso dos estruturalistas e pós-estruturalistas.
} 
blemas da infância são, assim, problemas da democracia e as garantias contidas nesse texto, uma forma de tentar salvaguardar esses direitos (SPOSATO, 2013, p. 49).

O Sistema de Garantias de Direitos, desenhado no ECA, prevê a atuação das instâncias governamentais e não governamentais em três eixos: defesa de direitos, promoção de direitos e controle do sistema. Para os fins deste trabalho, interessa-nos apenas o segundo dos eixos, o da promoção de direitos da infância e da juventude.

Essa promoção se dá através da concretização de políticas públicas, as quais, por sua vez, também se fracionam em três âmbitos: o das políticas básicas (saúde, educação, lazer), o das políticas especiais e o da política socioeducativa. Todos esses eixos são integrados e interdependentes. A política socioeducativa é a última intervenção que devem o Estado e demais organizações realizar. Em uma formulação mais simples, quando todos os outros âmbitos falham, impõem-se as medidas socioeducativas.

A política socioeducativa é um avanço, em muitos aspectos, mas essa formulação parece intrigante: a política socioeducativa só intervém quando as demais falham, portanto, as medidas são adequadas àqueles jovens que não tiveram acesso suficiente à escola, estão em situação de risco familiar e vulnerabilidade social? De que forma é possível interpretar essa premissa, sem cair nas simplórias interpretações etiológicas que encontram na pobreza a causa para o crime, reforçando estereótipos sobre as classes perigosas? Como os operadores da justiça lidam com as questões da vulnerabilidade social, familiar e pessoal na compreensão das medidas socioeducativas?

A doutrina da proteção integral é inaugurada em um Brasil ávido pela afirmação de direitos, em plena reconstrução do regime democrático. Não faltou boa intenção para a consagração de um modelo de responsabilização baseado na noção de que o/a jovem em conflito com a lei encontra-se em uma situação de acumuladas violações a seus direitos, conforme já pontuado.

Porém, a redemocratização conviveu com sopros autoritários que moldaram e moldam a atuação do sistema de justiça criminal (AZEVEDO, 
2005, p. 218). As notícias sobre violência dos agentes de segurança pública, aliadas a um fraco controle externo dessas atividades, mantiveram vivos os fantasmas das torturas, dos autos de resistência e das mortes sumárias (JESUS, 2010, p. 173-174; ABRAMOVAY; BATISTA, 2010, p. 30). Benoni Belli destaca que

A justificação da violência policial por parte de policiais parece derivar de uma percepção generalizada sobre o crescimento da criminalidade urbana e a necessidade de remédios radicais como modo de evitar que o mal se espraie por todo o tecido social. (BELLI, 2004, p. 30)

Essa manutenção do autoritarismo, que não nasce com ela, mas encontrou grande fôlego com a Doutrina da Segurança Nacional, que, por sua vez, fortaleceu-se durante o regime militar, reproduz-se não apenas na atividade policial. No âmbito judicial, ainda se manteve níveis elevados de negação de garantias processuais, com percentuais de presos provisórios que ultrapassam os 50\% em muitos estados brasileiros, por exemplo. Nossa realidade carcerária, por seu turno, muito se aproxima a narrativas de horror em que mortes, estupros e torturas jamais deixaram de ser comuns.

Como ressaltado em outro trabalho, segundo Valença e Castro (2014, p. 3):

As primeiras décadas de vida do ECA, foram, portanto, as do grande encarceramento, do populismo punitivo, do fortalecimento da cultura do medo, do aumento dos crimes letais intencionais, da reprodução de discursos sobre o crime baseados em conceitos de perigosismo social e do recrudescimento da guerra aos traficantes de drogas, representados como verdadeiros inimigos internos, que consagra a violência institucional como arma necessária no combate ao mal.

Como pensar em uma possibilidade de atualização de um projeto de proteção integral à infância e à juventude em um cenário como esse? Ao contrário, as décadas que sucederam à consagração da Doutrina da Proteção no Brasil foram propícias à formação da imagem de uma juventude 
perdida e indomável, tão comum ao longo da história criminalizadora de jovens ao longo do século XX (BATISTA, 2003)².

As constantes campanhas pela redução da maioridade penal, festejadas no Brasil pela mídia, apoiada em campanhas de opinião pública e reverberadas em projetos de lei no Congresso Nacional são a consequência mais evidente do desgosto em torno dos postulados da Proteção Integral (CAMPOS, 2009, p. 485).

No campo jurídico, os postulados da doutrina menorista permanecem justificando a internação de adolescentes e a negação a eles de garantias processuais penais ${ }^{3}$ em nome de sua proteção. Quando se passou para a execução da medida de internação, o quadro permanece o mesmo do sistema carcerário (MONTENEGRO; MACHADO, 2014): seletividade, função puramente de retribuição, impossibilidade de adoção de um modelo educativo, pinceladas do direito penal subterrâneo, reproduzido nos maus-tratos e torturas ainda praticados por agentes estatais (MALLART, 2014) e, claro, o descontrole dos agentes do sistema penitenciário, que cada vez mais negociam e acatam decisões dos chamados Comandos. Enfim, o sistema de justiça juvenil apresenta-se como uma reprodução, por vezes mais dramática, do sistema de justiça criminal.

Para abordar a nossa realidade, entretanto, é preciso entender que não se está falando apenas de adolescentes, mas de adolescentes meninas.

A partir da década de 1970, as contribuições da teoria social feminista vão se unir a postulados da criminologia e passar a abordar os aparelhos punitivos e os saberes a eles associados a partir do "ponto de vista situado" das mulheres. Os trabalhos mais clássicos da criminologia crítica de cunho feminista vão denunciar esses sistemas como reprodutores das desigualdades de gênero existente na sociedade e como última instância de controle sobre a mulher, quando as demais (família e igreja, por exemplo) falham. Como vítimas, merecerão a proteção do sistema punitivo se

\footnotetext{
${ }^{2}$ Em estudo sobre autos findos da justiça juvenil de 1968 a 1988, no Rio de Janeiro, Vera Malaguti Batista (2003) ressalta que a postura dos atores do campo da justiça estava voltada, sobremaneira, ao controle das indisciplinas comumente associadas à pobreza.

${ }^{3}$ A negação do efeito suspensivo à apelação no processo de apuração de atos infracionais é um exemplo evidente da violação ao princípio da presunção de inocência.
} 
corresponderem ao estereótipo da mulher honesta; se atoras de atos criminosos, serão duplamente punidas pela conduta e pelo descumprimento dos papeis tradicionais de mãe, filha e esposa.

Estabelecido o ponto de partida que orientou o nosso olhar sobre o campo, passa-se a descrever a forma como a pesquisa se desenvolveu e a problematizar os seus resultados.

\section{Aspectos Metodológicos}

A escolha do corpus da pesquisa foi determinada pelo material a que se teve acesso em razão de uma pesquisa realizada em Unidades de Internação femininas em diversos estados brasileiros e no Distrito Fede$\mathrm{ral}^{4}$. Neste último, das vinte meninas internadas na Unidade de Santa Maria - DF, na época da pesquisa, em abril de 2014, foram entrevistadas dez. Analisou-se, ainda, 17 do total de sentenças, já que, em um dos prontuários a decisão judicial estava ausente e, em dois deles, foram proferidas por magistrados/as de outras unidades da federação, tratando-se de duas adolescentes que tinham sido transferidas para o Distrito Federal. Sendo assim, fugia à nosso recorte de apenas analisar as sentenças de juízes e juízas daquela unidade da federação.

Com o material em mãos, procedeu-se a uma leitura "flutuante" (BARDIN, 2011, p. 126), procurando explorar a fala dos/as magistrados/ as e, ao mesmo tempo, das meninas.

Por óbvio, os documentos analisados permitia-nos caminhar por temáticas as mais diversas. Nas sentenças, por exemplo, pode-se perceber julgadores se posicionando sobre provas, o ato infracional, a criminalidade urbana, a juventude, o papel da punição, a legitimidade do poder judi-

\footnotetext{
${ }^{4} \mathrm{O}$ presente artigo é um dos frutos de nossa incursão em campo na pesquisa intitulada "Dos espaços aos direitos: a realidade da ressocialização na aplicação das medidas socioeducativas de internação das adolescentes do sexo feminino em conflito com a lei nas cinco regiões", cujo relatório foi publicado pelo Conselho Nacional de Justiça. Disponível em: <http://www.cnj.jus.br/files/conteudo/destaques/arquivo/2015/06/ cb905d37b1c494f05afc1a14ed56d96b.pdf>. Acesso em: 12 jan 2016
} 
ciário dentre tantos outros campos que, na análise de conteúdo, poderiam ser tratadas como categorias.

Interessava-nos, entretanto, a categoria presente de "trajetória desviante", já que, em grande medida era como os operadores da justiça viam as meninas. Partindo dessa categoria, foram estabelecidas mais algumas subcategorias relacionadas, dentre elas: desestrutura família, evasão escolar, renda familiar e uso de drogas.

As subcategorias foram estabelecidas a partir da própria leitura do material de análise. Nas sentenças, é possível perceber, quase sempre, meninas "perdidas" sendo desenhadas. Mais do que isso, eram perdidas e indomáveis. Conforme será tratado adiante, não se questiona uma situação socioeconômica, familiar e pessoal marcada por variadas formas de violências (estrutural, sexual, psicológica) de quase todas as adolescentes internadas. A questão que ficou é: como lidar com esse quadro? Compreendendo-o como um grande conjunto de causas que levaram, invariavelmente, ao crime?

Destaque-se, por fim, os processos nos quais constam as sentenças examinadas não serão identificados, considerando que se trata de autos que correm em segredo de justiça por envolver adolescentes. Portanto, serão apresentadas como sentenças 1, 2, 3 etc, de acordo com a nossa organização.

\section{Resultados: a construção social da adolescente infratora}

Em praticamente todas as sentenças analisadas - apenas uma foge à regra ${ }^{5}$ - observa-se que a trajetória de vida das meninas é narrada com a valorização de elementos de desorganização familiar, social, escolar e com referência ao uso de drogas ilícitas. Como argumenta Foucault (2013, p. 2):

\footnotetext{
${ }^{5}$ Nessa sentença, referente a uma adolescente a quem se imputou a prática de ato infracional análogo ao de tráfico de drogas, o juiz não tece um único comentário sobre as condições sociofamiliares e econômicas da adolescente. Ele se deteve nas considerações sobre o ato infracional e suas circunstâncias, aplicando a medida de internação em face de a adolescente já ter outras três passagens no sistema socioeducativo e pela gravidade do ato.
} 
Descrever seu caráter de delinquente, descrever o fundo das condutas criminosas ou paracriminosas que ele vem trazendo consigo desde a infância, é evidentemente contribuir para fazê-lo passar da condição de réu ao estatuto de condenado.

Nas leituras das decisões, percebe-se que a infância e a juventude que o modelo da proteção integral pretende proteger são antes vistos como perdidos e sem perspectiva. Perigosa e capaz das piores atrocidades. A imagem, em si, do crime em geral (MISSE, 2014). A pobreza e a desestrutura familiar e social, aliada a um discurso demonizador da droga e a um raciocínio etiológico positivista, fundado na busca das causas do crime, aliam pobreza à criminalidade de forma acrítica e cria um discurso que legitima o controle sobre as classes pobres, portanto, perigosas (ZAFFARONI, 2005, p. 145).

Nesse diapasão, a adolescente aqui representada pouco ou nada difere da figura do "menor" em situação de risco da Doutrina Tutelar. Tanto quanto este demanda intervenção estatal incapacitante. Como vítima e perigo para a sociedade, segue sendo objeto de controle. Isso tudo aliado a uma tendência em desacreditar no discurso ressocializador da pena e, por que não, da medida socioeducativa, faz com que a atuação sobre esses corpos que constituem a juventude-problema reproduza-se em respostas de estrita neutralização.

\subsection{A Desestrutura Familiar}

Para os magistrados, a "trajetória desviante" das adolescentes inicia-se com a desestrutura familiar. Quando é quebrado o padrão da família formada por casal heterossexual, enceta-se um ambiente de descontrole e falta de autoridade:

[...] a figura materna não constitui um referencial de autoridade e, ao contrário, a mãe tem sérias dificuldades em exercer um papel de proteção e condução adequada da educação dos filhos. Diante da fragilidade da adolescente devido à ausência de figura de referência sólida, ela tem sido constantemente corrompida por pares e adultos. (Sentença 5) 
A ausência paterna é comumente referida como fonte do desvio de comportamento das adolescentes:

[...] o pai continuou contato com a filha, levando-a para sua casa nos fins de semana, porém, quando Lorrani estava com 11 anos de idade, antes de iniciarem seus problemas de comportamento, o pai se mudou da região, tendo perdido contato com a filha. (Sentença 6)

A socioeducanda é uma jovem que se recusa a reconhecer a necessidade de observar as regras e normas intrafamiliares e que demonstra um preocupante envolvimento com a seara infracional [...] a jovem desmerece a autoridade paterna [...] igualmente não se sente obrigada a seguir as orientações que a genitora, em vão, busca impor-lhe. (Sentença 7)

Neste último caso, o questionamento à autoridade do pai e à orientação ${ }^{6}$ da mãe aparece como determinante na formação daquilo a que o/a juiz/juíza posteriormente se referiu como "[...] circunstâncias que a levaram ao envolvimento com o universo infracional". O padrão se repete:

O relatório social da UISS informa que a jovem foi adotada juntamente com seus irmãos de sangue. $\mathrm{O}$ casal adotante conviveu maritalmente por 34 anos e separou-se há dois anos. [...] A jovem mantem vínculo afetivo com o pai, no entanto, ele não exerce autoridade sobre a adolescente. [...] Tendo em vista o contexto social e pessoal das adolescentes, verifica-se que precisam de uma orientação mais adequada às suas vidas, para que lhe seja ministrado valores éticos e morais, de forma que possa elaborar um novo e consistente projeto de vida, através de trabalho lícito e escolarização. (Sentença 8)

Conforme se observa, as mães são sempre lembradas como incapazes de exercer o controle sobre as adolescentes, padrão comum de culpabilização da mulher ${ }^{7}$.

${ }^{6}$ Interessante notar como a autoridade é tarefa atribuída ao pai, ao passo que o aconselhamento ficaria a cargo da mãe. Esse padrão não apareceu nas demais sentenças. ${ }^{7}$ Muito curioso como esse é exatamente o mesmo padrão observado por Eleonora Brito em pesquisa realizada com autos da justiça juvenil de 1960 a 1990, do Distrito Federal. Portanto, 
O relatório avaliativo, fls. $\mathrm{X}$, informa em relação à adolescente $\mathrm{y}$, que os genitores estão separados há vários anos. Expõe que com a separação do casal, a representada passou a morar com o genitor, mas retornou ao lar materno, uma vez que o pai tenta lhe impor limites e a mãe comporta-se de forma permissiva ante sua rotina ociosa. Destaca que a jovem não estuda, convive com pessoas envoltas com a criminalidade e faz uso de entorpecente. [...] Observa-se desse modo que a personalidade da representada e o comprometido contexto social em que está inserida demonstram que pode dar continuidade à escalada delitiva, sendo dever do Estado evitar que isso ocorra, para a própria proteção da jovem. (Sentença 2)

os vínculos afetivos são frágeis, pois sua mãe e padrasto passam a maior parte do tempo fora de casa trabalhando e ambos não são reconhecidos pela jovem como referencial de autoridade. Tal adolescente não segue as regras e normas intrafamiliares, apresenta déficit entre sua idade cronológica e escolar e estava morando fora da casa na companhia de um namorado na época em que foi acautelada. [...] A aplicação do princípio da graduação na aplicação das medidas socioeducativas previstas na legislação menorista deve ser o norte a guiar o juiz nesse momento crucial da sentença. No entanto, ao se deparar com o caso concreto, às vezes, é necessário que saia da progressão das medidas para aplicar aos adolescentes infratores a mais severa das medidas previstas, mormente quando o relatório social traz, em sua expressa maioria, condições sociais e pessoais desfavoráveis aos representados. (Sentença 9)

As adolescentes que não mais residiam com os pais, morando com amigos ou companheiros, também são um retrato da tragédia desviante, possuindo uma "carreira de indisciplinas" (BRITO, 2007, p. 230) que se inicia na desestrutura familiar, perpassa o abandono do lar e culmina no ato infracional:

a racionalidade utilizada para explicar o crime e aplicar a medida no âmbito da justiça de menores, ultrapassa as fronteiras da legislação da Proteção Integral para permanecer tratando a juventude-perdida como um problema de família desestruturada, recaindo sobre a mãe grande parte da "culpa" pelo insucesso da filha (BRITO, 2007, . p. 187). 
Y declarou cursar a $7^{\mathrm{a}}$ série do ensino fundamental, estagiar no TSE, fazer uso de substâncias entorpecentes e residir com duas amigas. [...] O relatório social aponta que os genitores estão separados há dez anos e, nesse contexto, o pai tornou-se ausente afetivamente, apesar de auxiliar nas despesas dos filhos [...]. Relata que Y possui histórico de repetências e desinteresse pelo âmbito escolar, tendo repetido a $6^{\mathrm{a}}$ série e, há três anos, frequenta a $7^{\mathrm{a}}$ série do ensino fundamental [...] A equipe técnica verificou que os vínculos afetivos entre a jovem e sua família estão preservados, mas a genitora possui dificuldade em exercer efetivo controle sobre a rotina da filha. O fato de a jovem não residir juntamente com a família, ou seja, sem supervisão de um responsável denota essa circunstância [...] A mãe expõe ter ciência de que a filha faz uso de tabaco e álcool, sendo que, aproximadamente uma semana antes do evento delitivo, tomou conhecimento que $\mathrm{Y}$ faz uso de rohypnol adicionado a bebidas alcoolicas. [...] Observa-se, desse modo, que a personalidade da representada e o contexto social em que está inserida demonstram que pode dar continuidade à escalada delitiva. (Sentença 4)

\subsection{A Defasagem Escolar e a Preguiça para o Trabalho}

Com a estrutura familiar há uma grande ênfase no descompasso e na evasão escolar das adolescentes:

[...] é a quarta vez que a representada é internada provisoriamente em razão da prática de atos infracionais. Ela abandonou os estudos em 2009, na $5^{\text {a }}$ série do ensino fundamental, e passou a fazer uso constante de drogas, principalmente maconha, cocaína e rohypnol [...] Há aproximadamente 08 meses havia saúdo de casa para morar com o namorado, Olival de 25 anos. A mãe não concordou com a união [...] mas também não teve autoridade suficiente para impedi-a de sair de casa. [...] Pouco antes de seu acautelamento, ela voltou a sair da casa materna para morar com um grupo de amigas em um imóvel sustentado pela renda auferida a partir do tráfico de drogas. (Sentença 3 , grifos nossos)

Y e Z contam, respectivamente, 16 e 13 anos e não registram outra passagem por este Juízo. Em juízo, dissertam que estão matricula- 
das na rede de ensino, não trabalham e residem com as genitoras. Stephanie Gomes acrescentou fazer uso de maconha. Na mesma ocasião, os responsáveis pelas jovens informaram não possuir controle sobre as adolescentes, uma vez que andam em más companhias, não frequentam as aulas e administram suas vidas conforme suas demandas. (Sentença 1)

Além do desinteresse escolar, há constantemente nas sentenças a informação de que elas não trabalham. Uma das adolescentes, no caso mencionado, tem 13 anos, mas questionou-se, ainda assim, se ela desempenhava alguma atividade laboral. Quantas adolescentes trabalham com essa idade? Quais trabalham? Parece que nem mesmo o magistrado põe fé em suas vidas escolares.

\subsection{O Uso de Drogas}

O uso de drogas soma-se a esse cenário de forma devastadora. A abordagem sobre a droga no poder judiciário é tendente a operar a partir de estereótipos do tipo usuário-dependente e traficante-inimigo (DEL OLMO, 1990). A irracionalidade que toma o debate impede qualquer ponderação sobre variáveis que um tema tão vasto apresenta. No caso das adolescentes, a droga é mais um componente da "carreira de indisciplinas" que, junto aos demais já tratados, torna a vida criminosa inevitável e a necessidade da medida extrema, inquestionável. Abordagens moralizantes e punitivas se dirigem em relação às meninas que afirmam já terem usado algum tipo de droga.

[...] a jovem, com 14 anos de idade, encontra-se em situação de elevada vulnerabilidade social, altamente embrenhada no uso de drogas ilícitas e não podendo contar satisfatoriamente com seu núcleo familiar, a indicar a necessidade de ações extremas por parte do Estado. Ela frequentava tratamento no adolescentro há aproximadamente dois anos, com indicação para internação em clínica de tratamento a toxicômanos, porém, os resultados têm sido insatisfatórios, uma vez que a situação de drogadição e desorganização familiar estão se agravando, o que dificulta inclusive sua adesão a 
qualquer proposta de tratamento. Observa-se que o núcleo familiar da jovem não se mostrou apto à orientá-la e inibir seu impulso infracional [...] Nesta perspectiva fática/legal, manter a representada em liberdade ou semiliberdade contribuiria direta e intensamente para formar uma conviç̧ão de impunidade, bem como lhe proporcionaria vivenciar os mesmos estímulos infracionais que encontrou. (Sentença 5)

Percebe-se na fala desse/a magistrado/a que a adolescente está completamente perdida no vício da droga. Ninguém consegue freá-la, pois ate mesmo o tratamento foi, por ela abandonado. Diante disso, é fundamental puni-la para que não paire o sentimento de impunidade e ela não permaneça refém dos "estímulos infracionais". Torna-se frequente a citação de termos como "personalidade", "estímulo infracional", "instinto", perfazendo uma imagem da mulher delinquente com o qual a criminologia tradicional sempre operou (HEIDENSON; GELSTHORPE, 2007).

Observa-se nesses discursos que a criminalização da droga transcende as condutas previstas como crimes na Lei de Drogas (Lei n. 11.343/06). O uso e a experimentação de entorpecentes constituem verdadeiras "faltas sem infração", sobre a que já se falou, que pune as meninas, independentemente do ato infracional a elas atribuído. Uma das sentenças pareceu bem emblemática desse potencial criminalizador da narrativa da droga. $\mathrm{O}$ caso era de $\mathrm{Y}$, que matou, juntamente com $\mathrm{Z}$, seu namorado, um homem que a explorava sexualmente.

Ao referir-se a ele, disse o juiz: " $Z$. não registra antecedentes infracionais, mas já fez uso de substâncias entorpecentes, sem desenvolver a dependência química (Sentença 10).

O uso da droga relativiza e ameniza a primariedade do adolescente. Apesar de nunca ter passado pelo sistema socioeducativo, praticou um "delito" talvez até mais grave: ser usuário de drogas. Logo em seguida, ao falar sobre Y, o juiz complementa a criminalização do uso da droga como aspecto tão ou mais importante que o ato em si praticado pelos jovens:

$\mathrm{O}$ relatório social referente à jovem $\mathrm{Y}$ informa que ela não registra histórico de passagens anteriores pelo sistema socioeducativo, estu- 
dante de ensino médio sem grande defasagem entre a sua idade cronológica e a escolar [...] A jovem é usuária de maconha, e, segundo ela, por influência do namorado Z. (Sentença de 10)

A adolescente não era protagonista de uma trajetória perdida, como as demais meninas. Vinha de família estruturada, estudava e ainda fazia curso de operadora de caixa, pretendendo, portanto, obter um emprego fixo. Porém, era usuária de maconha.

A droga ainda constitui a personalidade das adolescentes. Se a personalidade delas é desvirtuada, o uso de drogas agrava o descontrole e a incapacidade de freios. Leva as meninas a uma vida sexual promíscua e que não merece proteção. $O$ caso a seguir é a de uma adolescente que, ao acordar e perceber que fora vítima de violência sexual, matou o suposto agressor:

Extrai-se dos autos que, na noite anterior aos fatos, a representada reuniu-se com conhecidos para comemorarem o aniversário de uma amiga, y, ocasião em que ingeriu grande quantidade de bebida alcoólica. Momento seguinte, já embriagada, a representada decidiu circular pela rua, oportunidade em que se encontrou com a vítima e dirigiram-se para a residência dela. Nesse local, após continuarem consumindo bebida alcóolica, a vítima e a representada adormeceram-se. Ao acordar, em instantes depois, a representada, imaginando ter sido violentada sexualmente pela vítima e tendo observado que a porta do imóvel se encontrava trancada, passou a gritar por ajuda, oportunidade em que foi auxiliada pelo imputável M e N, e uma terceira pessoa ainda não identificada, que, ao entrarem na residência, somaram-se à representada e todos passaram a agredir violentamente a vítima. (Sentença 16, grifos nossos)

No texto, menciona-se o uso de álcool três vezes antes de se referir à justificativa apresentada pela adolescente para a prática do crime. Aqui não nos interessa se é justificável ou não o ato, mas apenas o fato de que, de um lado, há a fala de uma autoridade judicial e, do outro, a de uma menina embriagada que, errante, sai pelas ruas à noite e vai dormir na casa de um rapaz. 
Edwin Schur nota que em um processo de interação entre uma agência estatal de controle e um "selecionado" não há como afirmar que ambos competem da mesma forma para verem prevalecer suas falas e posições. Ele comenta que os agentes do controle

[...] são comumente vistos como sendo especialistas desinteressados trabalhando "para o interesse público", enquanto o suspeito ou os identificados como desviantes são vistos como pessoas que perseguem apenas seus próprios interesses, os quais, por definição, já tendem a serem vistos como socialmente ofensivos. (SCHUR, 1979, p. 338)

Essa certa desqualificação moral e jurídica do réu é evidente no caso em tela. Não é possível acolher uma defesa como essa de alguém sobre quem recai enorme suspeita a respeito da idoneidade da vida sexual. Logo em seguida, o juiz, mesmo afirmando que houve perícia sexológica inconclusiva, opta por ignorar a tese:

No caso em comento, não houve comprovação de que a representada realmente foi submetida à agressão imputada ao ofendido. O laudo de exame de corpo de delito - atos libidinosos e lesão corporal, fls. X, restou inconclusivo, havendo, assim, apenas a versão da jovem acerca do fato. [...] Além disso, ainda que tivesse havido relação sexual entre a representada e a vítima, não há nenhum elemento nos autos que indique o não consentimento da representada na eventual relação. (Sentença 16)

\section{Discussão: trajetórias de indisciplina na construção da seleti- vidade do sistema punitivo}

As consequências do estigma de "menina perdida" são muitas. Dentre elas, a de tornar incontornáveis os processos de seleção dos sistemas de controle que preferencialmente passam a recair sobre elas.

A grande questão aqui é como articular e considerar os vários elementos de vulnerabilidade, alguns dos quais amplamente relacionados à 
pobreza, sem torna-los condicionantes para a prática de crimes. Empreender esse esforço é fugir às construções que veem nessa adolescente a feição, em si, do perigo e do crime.

O conceito de "sujeição criminal", desenvolvido por Michel Misse, pode ser elucidativo para explicar esse círculo interpretativo que entende as desorganizações na vida das adolescentes como causa do crime e acaba por identificar nelas o crime em si. "Sujeição criminal", segundo o autor, "[...] refere-se ao processo social pelo qual se dissemina uma expectativa negativa sobre indivíduos ou grupos, fazendo-os crer que essa expectativa não só é verdadeira como constitui parte integrante de sua subjetividade" (MISSE, 2014, p. 204). E ele conclui:

A sujeição criminal é a expectativa de que determinados indivíduos e grupos sociais, que apresentam determinadas características, tenham propensão a cometer crimes, especialmente violentos, e que essa propensão é parte inelutável de sua personalidade e caráter, de sua subjetividade de seu ser. (MISSE, 2014, p. 209)

Michel Foucault também trabalha com a constituição dessa figura perigosa na justiça penal. Manuseando exames psiquiátricos realizados no bojo de processos criminais nas décadas de 1950 e 1960, ele demonstra como elementos extrapenais como constituição familiar, comportamento infantil e até mesmo gostos e gestos aparecem no processo para formar o objeto da acusação. Réus e rés são julgados não pelos fatos cometidos, mas pelo conjunto de atributos sociais, familiares e psicológicos entendidos como desfavoráveis e, quiçá, responsáveis pelo crime.

Essa descrição da personalidade e das tendências sociais e psicológicas do acusado ficava a cabo dos exames psiquiátricos, documentos dotados de uma legitimidade proveniente do discurso cientificista positivista que, ainda durante o século XX - e até hoje - permeia a formação da verdade processual. A função do exame era, portanto, a de "[...] mostrar como o indivíduo já se parecia com o seu crime antes mesmo de o ter cometido [...]", ao "[...] descrever seu caráter de delinquente, descrever o fundo das condutas criminosas ou paracriminosas que ele vem trazendo 
consigo desde a infância" fazendo passar "condição de réu ao estatuto do condenado." (FOUCAULT, 2013, p. 18 e 21).

Em alguma medida, as modificações pelas quais passaram as políticas de atendimento à infância e à juventude, com a consagração da Doutrina da Proteção Integral no Brasil, procuraram imprimir nesse jovem papeis positivos de protagonismo e de sujeito de direitos. Porém, conforme já pontuado acima, as constantes correlações entre política socioeducativa e assistencial, com a compreensão daquelas como medidas aplicáveis a adolescentes que não acessaram políticas universais de direitos sociais, mantem a adolescência pobre como alvo preferencial das instâncias de controle punitivo (PAULA, 2015, p. 41).

Sendo assim, as sentenças judiciais analisadas acabam por realizar essa tarefa. Não apenas se retratam um fato delituoso, mas nomeia um tipo social criminoso. Esse tipo social perigoso são as adolescentes pobres.

\section{Conclusão}

Talvez a melhor contribuição da Teoria do Etiquetamento tenha sido a de estabelecer o crime não como uma realidade ontológica, mas relacional, fruto de relações de interação e, portanto, uma construção social. Os atores do sistema punitivo atuam a partir de concepções sobre o crime e o criminoso, mediados, evidentemente, pelos aparatos legais.

Nessas sentenças, percebe-se ser construída uma adolescente tipicamente criminosa, através da valorização de atributos da pobreza. Mediante um raciocínio tipicamente etiológico, a situação de vulnerabilidade das adolescentes é interpretada como causa para o ato infracional, gerando-se a velha associação entre pobreza e criminalidade. Se ser assim é ser criminoso, a pobreza é identificada com a classe perigosa. Aos dados estritamente socioeconômicos se somam, para compor o quadro mais geral do sujeito perigoso, as avaliações de cunho moral que vão desde considerações sobre a conduta sexual da adolescente até o uso de entorpecentes.

O discurso socioeducativo comprometido com a garantia de direitos da infância e da juventude reproduz-se como o mais antigo argumento 
criminológico do perigosismo social que vislumbra as causas do crime na pobreza, desestrutura familiar, escolar e laboral e no uso de drogas. Longe de constituir um fator de proteção, a trajetória das adolescentes opera positivamente na construção da sujeição criminal. Desse modo, os juízes compreendem que outra solução não resta, a não ser puni-las pelos atos e interná-las como forma de proteger a sociedade, tudo sob o manto de sua proteção.

Por fim, como é possível encarar a situação de vulnerabilidade dessas adolescentes mais selecionadas pelo sistema de justiça juvenil sem cair na confirmação de uma estereotipação que permite um fácil deslizamento entre vulnerabilidade e crime? Antes de tudo, talvez seja preciso se despir um pouco dos termos e das categorias do próprio sistema punitivo e do senso comum, por vezes, ainda tão presentes nas reflexões criminológico críticas.

É preciso considerar que a responsabilização de adolescentes pela prática de atos infracionais não pode estar amparada em discursos patologizantes, que promovem deslizes semânticos que vão da vulnerabilidade à criminalidade como em um piscar de olhos. Do contrário, se estará persistindo nas matrizes positivistas e etiológicas que identificam a pobreza como fator gerador de criminalidade.

\section{Referências}

ABRAMOVAY, Pedro V.; BATISTA, Vera Malaguti. (Org.). Depois do grande encarceramento. Rio de Janeiro: Revan, 2010.

AZEVEDO, Rodrigo Ghiringuelli de. Criminalidade e justiça penal na América Latina. Sociologias, Porto Alegre, ano 7, n. 13, jan.-jun. p. 212241, 2005.

BATISTA, Vera Malaguti. Difíceis ganhos fáceis: drogas e juventude pobre no Rio de Janeiro. Rio de Janeiro: Editora Revan, 2003.

BARDIN, Laurence. Análise de conteúdo. São Paulo: Edições 70, 2011. 
BELLI, Benoni. Tolerância zero: tolerância zero e democracia no Brasil - visões da segurança pública na década de 90. São Paulo: Perspectiva, 2004.

BRITO, Eleonora Zicari Costa de. Justiça e gênero: uma história da justiça de menores em Brasília (1960-1990). Brasília, DF: Editora UnB/ FINATEC, 2007.

CAMPOS, Marcelo da Silveira. Mídia e Política: a construção da agenda nas propostas de redução da maioridade penal na Câmara dos Deputados. Opinião Pública, Campinas, v. 15, n. 2, novembro, p. 478-509, 2009.

CHALHOUB, Sidney. Trabalho, lar e botequim: o cotidiano dos trabalhadores no Rio de Janeiro da belle époque. 3. ed. Campinas: Editora Unicamp, 2012.

CHANTER, Tina. Gênero: conceitos-chave em filosofia. Porto Alegre: Artmed, 2011.

DEL OLMO, Rosa. A face oculta da droga. Rio de Janeiro: Revan, 1990.

FOUCAULT, Michel. Os anormais. São Paulo: Martins Fontes, 2013.

HEIDENSON, Frances; GELSTHORPE, Loraine. Gender and crime. In: MAGUIRE, M.; MORGAN, Rod; REINER, R. The Oxford Handbook of Criminology. 4. ed. Oxford: University Press, 2007.

JESUS, Maria Gorete Marques de et al. Prisão provisória e lei de drogas: um estudo sobre os flagrantes de tráfico de drogas na cidade de São Paulo. 2014. Disponível em <http://www.defensoria.sp.gov. br/dpesp/Repositorio/23/Documentos/2011.12.20 Pris\%C3\%A3o\%20 Provis\%C3\%B3ria\%20e\%20Lei\%20de\%20Drogas\%20 $\%$ E2\%80\%93\%20Um\%20estudo\%20sobre \%20os\%20flagrantes $\% 20$ de $\% 20 \operatorname{tr} \%$ C3\%A1 fico $\% 20$ de $\% 20$ drogas $\% 20$ na $\% 20$ cidade $\% 20$ de $\% 20$ S\%C3\%A3o\%20Paulo.pdf >. Acesso em: 16 fev. 2016

KITSUSE, John I. Societal reaction to deviant behavior: problems of theory and method. In: BECKER, Howard (Org.). The other side: perspectives on deviance. Toronto: The Free Press of Glencoe, 1964. p. $87-102$. 
MALLART, Fábio. Cadeias dominadas: a Fundação CASA, suas dinâmicas e as trajetórias de jovens internados. São Paulo: Terceiro Nome, 2014.

MISSE, Michel. Sujeição criminal. In: AZEVEDO, Rodrigo G. de; LIMA, Renato; RATTON, José Luiz. (Org.). Crime, polícia e justiça no Brasil. São Paulo: Editora Contexto, 2014.

MELLO, Marília Montenegro Pessoa de et al. Dos espaços aos direitos: a realidade da ressocialização na aplicação das medidas socioeducativas de internação das adolescentes do sexo feminino em conflito com a lei nas cinco regiões. Brasília: Conselho Nacional de Justiça, 2015. Disponível em: <http://www.cnj.jus.br/files/conteudo/destaques/ arquivo/2015/06/cb905d37b1c494f05afc1a14ed56d96b.pdf $>$. Acesso em: 16 fev. 2016.

MELLO, Marília M. P. de; AMARAL, Érica B. L. do. Seletividade e socioeducação as condicionantes da criminalização juvenil: pobreza e patriarcado - um olhar criminológico sobre a realidade socioeconômica das adolescentes do sexo feminino cumprondo medida socioeducativa de internação em Recife. In: ANDRADE, Vera R. P. de; ÁVILA, Gustavo Noronha de.; CARVALHO, Gisele M. de. (Org). Criminologias e política criminal. 1. ed. Florianópolis: CONPEDI/UFSC, 2014. v. 1, p. 500-529.

PAULA, Liana de. Da "questão do menor" à garantia de direitos: discursos e práticas sobre o envolvimento de adolescentes com a criminalidade urbana.Civitas, Porto Alegre, v. 15, n.1, jan.-mar., p. 27 43, 2015.

SCHUR, Edwin M. Interpreting deviance: a sociological introduction. New York: Harper \& Row Publishers, 1979.

SPOSATO, Karyna B. O direito penal juvenil. São Paulo: Saraiva, 2013.

. Princípios e garantias para um direito penal juvenil mínimo.

In: INSTITUTO LATINOAMERICANO PARA LA PREVENCIÓN DEL DELITO Y TRATAMIENTO DEL DELINCUENTE, Associação Brasileira de Magistrados e Promotores de Justiça da Infância e da 
Juventude, Brazil. Secretaria Especial dos Direitos Humanos, United Nations Population Fund (Orgs.). Justiça, adolescente e ato infracional: socioeducação e responsabilização. São Paulo: ILANUD, 2006, p. 247275.

VALENÇA, Manuela Abath; CASTRO, Helena Rocha Coutinho de. A construção da adolescente traficante de drogas: uma análise de sentenças que aplicam medida de internação no Distrito Federal. In: BRAGA, Rômulo Rhemo Palitot; ÁVILA, Gustavo Noronha de; RIBEIRO, Luiz Gustavo Gonçalves (Org.). Criminologias e política criminal I. 1. ed. Florianópolis: CONPEDI, 2014. v. I, p. 10-30.

ZAFFARONI, Eugenio Raúl. Las classes peligrosas: el fracasso de um discurso policial prepositivista. Sequência: Estudos Jurídicos e Políticos, Florianópolis, ano XXV, p. 141-168, dez. 2005.

ZALUAR, Alba. Integração perversa. Rio de Janeiro: Editora FGV, 2004.

Marília Montenegro Pessoa de Melo é professora da graduação e do programa de pós-graduação da Universidade Católica de Pernambuco, professora da Universidade Federal de Pernambuco, coordenadora do grupo Asa Branca de Criminologia, doutora pela Universidade Federal de Santa Catarina e mestre pela Universidade Federal de Pernambuco.

E-mail: mariliamontenegro@yahoo.com.br.

Endereço profissional: Universidade Católica de Pernambuco, Centro de Ciências Jurídicas, Rua do Príncipe, n. 526, Boa Vista, Recife, PE. CEP: 50050-900.

Manuela Abath Valenca é doutoranda em Direito pela Universidade de Brasília, mestre pela Universidade Federal de Pernambuco, professora da Universidade Federal de Pernambuco e da Universidade Católica de Pernambuco e pesquisadora no grupo Asa Branca de Criminologia.

E-mail: manuelaabath@gmail.com.

Endereço profissional: Universidade de Brasília, Faculdade de Direito, Campus Universitário Darcy Ribeiro, Brasília, DF. CEP: 70919-970. 
